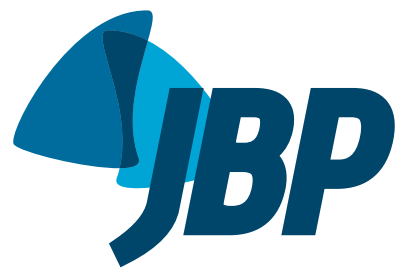

\title{
Sleep-disordered breathing in patients with COPD and mild hypoxemia: prevalence and predictive variables
}

\author{
José Laerte Rodrigues Silva Júnior ${ }^{1,4}$, Marcus Barreto Conde ${ }^{2,3}$, \\ Krislainy de Sousa Corrêa ${ }^{4}$, Helena Rabahi ${ }^{4}$, Arthur Alves Rocha ${ }^{5}$, \\ Marcelo Fouad Rabahi1,4
}

1. Faculdade de Medicina, Universidade Federal de Goiás, Goiânia (GO) Brasil.

2. Instituto de Doenças do Tórax, Universidade Federal do Rio de Janeiro, Rio de Janeiro (RJ) Brasil.

3. Faculdade de Medicina de Petrópolis/ Faculdade Arthur Sá Earp Neto - FMP/ FASE - Petrópolis (RJ) Brasil.

4. Clínica do Aparelho Respiratório CLARE - Goiânia (GO) Brasil.

5. Centro Médico, Goiânia (GO) Brasil.

Submitted: 24 February 2016. Accepted: 5 October 2016

Study carried out at the Centro de Pesquisa Clínica, Clínica do Aparelho Respiratório - CLARE - Goiânia (GO) Brasil.

\begin{abstract}
Objective: To infer the prevalence and variables predictive of isolated nocturnal hypoxemia and obstructive sleep apnea (OSA) in patients with COPD and mild hypoxemia. Methods: This was a cross-sectional study involving clinically stable COPD outpatients with mild hypoxemia (oxygen saturation $=90-94 \%$ ) at a clinical center specializing in respiratory diseases, located in the city of Goiânia, Brazil. The patients underwent clinical evaluation, spirometry, polysomnography, echocardiography, arterial blood gas analysis, six-minute walk test assessment, and chest X-ray. Results: The sample included 64 patients with COPD and mild hypoxemia; 39 (61\%) were diagnosed with sleep-disordered breathing (OSA, in 14; and isolated nocturnal hypoxemia, in 25). Correlation analysis showed that $\mathrm{PaO}_{2}$ correlated moderately with mean sleep oxygen saturation $(r=0.45 ; p=0.0002)$, mean rapid eye movement (REM) sleep oxygen saturation ( $r=0.43 ; p=0.001)$, and mean non-REM sleep oxygen saturation ( $r=0.42 ; p=0.001)$. A cut-off point of $\mathrm{PaO}_{2}$ $\leq 70 \mathrm{mmHg}$ in the arterial blood gas analysis was significantly associated with sleepdisordered breathing $(\mathrm{OR}=4.59 ; 95 \% \mathrm{Cl}: 1.54-13.67 ; \mathrm{p}=0.01)$. The model showed that, for identifying sleep-disordered breathing, the cut-off point had a specificity of $73.9 \%$ (95\% Cl: 51.6-89.8\%), a sensitivity of 63.4\% (95\% Cl: 46.9-77.9\%), a positive predictive value of $81.3 \%$ (95\% Cl: $67.7-90.0 \%)$, and a negative predictive value of $53.1 \%$ (95\% $\mathbf{C l}$ : 41.4-64.4\%), with an area under the ROC curve of 0.69 (95\% Cl: $0.57-0.80)$, correctly classifying the observations in $67.2 \%$ of the cases. Conclusions: In our sample of patients with COPD and mild hypoxemia, the prevalence of sleep-disordered breathing was high (61\%), suggesting that such patients would benefit from sleep studies.

Keywords: Pulmonary disease, chronic obstructive/complications; Sleep wake disorders/ epidemiology; Anoxia/etiology.
\end{abstract}

\section{INTRODUCTION}

The presence of sleep-disordered breathing among patients with COPD appears to be associated with an increased risk of exacerbations and with difficulty in therapeutic management. ${ }^{(1,2)}$ Although the recommendation is that the presence of sleep-disordered breathing conditions be investigated in the history taking of such patients, these conditions frequently go unnoticed by the physician and/or the patient. ${ }^{(3)}$

Sleep-disordered breathing conditions such as obstructive sleep apnea (OSA) and isolated nocturnal hypoxemia (oxygen desaturation in the absence of OSA) occur in patients with COPD at a prevalence ranging from $8 \%$ to $39 \%$ and from $27 \%$ to $84 \%$, respectively. ${ }^{(3-18)}$ Apparently, the prevalence of sleep-disordered breathing is associated with the severity of COPD, because it has been demonstrated that subjects with COPD and an oxygen saturation less than $90 \%$ may have pronounced drops in oxygen saturation during sleep. ${ }^{(3,11)}$ However, there is no consensus regarding the evaluation of sleep-disordered breathing in patients with COPD who have mild daytime hypoxemia (oxygen saturation between $90 \%$ and $94 \%)^{(4,5,19)}$ In addition, polysomnography, a test used to diagnose OSA and nocturnal hypoxemia, is not formally indicated in this subgroup of patients with COPD, and the prevalence of these sleep-disordered breathing conditions in this subgroup is unknown. ${ }^{(4,5)}$

The objective of the present study was to infer the prevalence of and identify predictive variables associated with sleep-disordered breathing (OSA and isolated nocturnal hypoxemia) in patients with COPD and mild daytime hypoxemia (oxygen saturation between $90 \%$ and 94\%).

\section{METHODS}

Subjects, methodological design, and ethical aspects

This was a cross-sectional study conducted at the Clinical Research Center of the Clínica do Aparelho Respiratório,

Correspondence to:

José Laerte R. Silva Júnior. Avenida Universitária, Km 3,5, Cidade Universitária, CEP 75083-515, Anápolis, G0, Brasil.

Tel.: 5562 8434-9431. Fax: 5562 3534-8032. E-mail: joselaertej@@gmail.com

Financial support: This study received financial support from Novartis S.A. Novartis played no role in the design, methods, data management, or analyses of this study or in the decision to publish it. José Laerte R. Silva Júnior is the recipient of a Hopkins-Brazil International Clinical Operational Research Training Award, funded by the Fogarty International Center/National Institutes of Health [Grant no. USNIH \# U2R TW006885 ICOHRTA] 
which is a clinic specializing in respiratory diseases, located in the city of Goiânia, Brazil.

Patients with a previous diagnosis of COPD who were not on home oxygen therapy, were clinically stable, and were $\geq 40$ years of age, all of whom were admitted to the Clinical Research Center of the Clínica do Aparelho Respiratório between April 1 and September 31 of 2013, were considered eligible for and invited to participate in the study. After giving written informed consent, patients underwent spirometry and oximetry. Subjects who had a post-bronchodilator $\mathrm{FEV}_{1} / \mathrm{FVC}$ ratio $<70$; had oximetry results showing mild daytime hypoxemia (oxygen saturation between $90 \%$ and $94 \%$ ); were not knowingly pregnant or had menstruated in the last 28 days (in the case of female participants); had no history of recent myocardial infarction (within three months); had no medical history of asthma or any other concomitant lung disease; had no history of cancer diagnosis; had no history of renal failure or dialysis; had no history of insulin-dependent diabetes; and had no complaints related to snoring, witnessed apneas, or excessive daytime sleepiness were included in the study. All study subjects then underwent clinical evaluation and completed validated instruments-the Medical Research Council dyspnea scale, ${ }^{(20)}$ the COPD Assessment Test, ${ }^{(21)}$ and a classification of socioeconomic level. ${ }^{(22)}$ Subsequently, they underwent a six-minute walk test (6MWT), completed the Epworth Sleepiness Scale, ${ }^{(23)}$ and underwent polysomnography, echocardiography, arterial blood gas analysis, and posteroanterior and lateral chest X-ray. Subjects with $\mathrm{P} \mathrm{PaO}_{2}<60$ $\mathrm{mmHg}$ by resting arterial blood gas analysis and/or radiographic evidence of any significant abnormality not attributable to COPD were excluded from the study. Subjects who were unable to understand or complete all instruments and interviews were also excluded. The present study was conducted in accordance with Good Clinical Practice and was approved by the Ethics Committee of the Hospital Geral de Goiânia (Protocol no. 198.344/2013).

\section{Procedures and definitions}

Clinical stability was defined as no exacerbation in the preceding four weeks. ${ }^{(24)}$ All subjects were categorized by smoking status as smokers (subjects who were currently smoking daily or less than daily); former smokers (subjects who had smoked at least 100 cigarettes or 5 packs in their lifetime and had quit smoking); or nonsmokers (subjects who had never smoked or had smoked fewer than 100 cigarettes or 5 packs in their lifetime). ${ }^{(25)}$

Subjects were classified as having COPD according to the Global Initiative for Chronic Obstructive Lung Disease 2014 criteria (chronic respiratory symptoms, a history of exposure to risk factors for the disease, and a post-bronchodilator $\mathrm{FEV}_{1} / \mathrm{FVC}$ ratio $<70$ on spirometry). ${ }^{(2)}$

Nocturnal hypoxemia was defined as an oxygen saturation $<90 \%$ for at least 5 min on polysomnography, with a nadir $\leq 85 \%$. ${ }^{(14)}$ Subjects were considered to have isolated nocturnal hypoxemia if their sleep study showed nocturnal hypoxemia but no OSA. ${ }^{(11)}$

Desaturation during the 6MWT was defined as a $\geq$ $4 \%$ drop in resting oxygen saturation during at least the last 3 min of the test. (26)

Polysomnography was performed with the Alice 5 Diagnostic Sleep System (Philips Respironics, Murrysville, PA, USA) in a sleep laboratory. Apnea was defined as airflow cessation $\geq 10 \mathrm{~s}$, and hypopnea was considered present when at least one of three conditions occurred: a $>50 \%$ reduction in airflow; a $>50 \%$ reduction in airflow and a $>3 \%$ drop in oxygen saturation; or a $>50 \%$ reduction in airflow and electroencephalographic evidence of arousal. OSA was considered present when the apnea-hypopnea index $(\mathrm{AHI})$ was $\geq 15$ events/h (a definition aimed at being a more stringent diagnostic criterion and at reducing the possibility of overestimating the presence of OSA because of the possible presence of excessive daytime sleepiness in patients with COPD). Recordings were interpreted and sleep stages were determined according to the recommendations of the American Academy of Sleep Medicine. ${ }^{(27)}$

\section{Sample size calculation}

To calculate the sample size for the prevalence study, we estimated a proportion of the population with specific absolute accuracy by using the formula $\mathrm{n}=\mathrm{z}^{2}{ }_{1-\mathrm{a} / 2} \mathrm{P}(1-\mathrm{P}) / \mathrm{d}^{2}$. $^{(28)}$ Because prevalence rates of sleep-disordered breathing demonstrate a wide range of values across studies (from $8 \%$ to $84 \%$ ), ${ }^{(6-14)}$ in the sample size calculation for the cross-sectional study, we assumed a $50 \%$ prevalence of sleep-disordered breathing as the safest choice, given that this value would yield the biggest sample size. To estimate the prevalence of sleep-disordered breathing with an absolute accuracy of $13 \%$ and a confidence level of $95 \%$, the sample size was calculated as 57 subjects. Assuming a potential error of $10 \%$, we decided to include at least 64 subjects in the sample.

\section{Statistical analysis}

The results were analyzed with the STATA program, version 13.1 (StataCorp LP, College Station, TX, USA), using a level of significance of $5 \%(p<0.05)$. Data normality was assessed by using the Shapiro-Wilk test. Quantitative variables with normal distribution were expressed as mean and standard deviation, quantitative variables with non-normal distribution were expressed as median and interquartile range (IQR), and qualitative variables were expressed as proportions.

ANOVA was used to compare means, with Tukey's post hoc test being used to identify significant differences, whereas ANOVA with the Kruskal-Wallis post hoc test was used to compare medians. For dichotomous variables, the chi-square test or Fisher's exact test, when appropriate, was used. Logistic regression was used to calculate the odds ratios of the association between the independent or predictive variable and the outcome 
variable (one of the two sleep-disordered breathing conditions studied here) with $95 \%$ CIs. The cut-off value for $\mathrm{PaO}_{2}$ was calculated by ROC curve analysis. A correlation analysis was performed to evaluate the strength of the linear relationship between numerical variables, with Bonferroni adjustment of significance levels, and multiple linear regression was conducted to study the cause-and-effect relationship.

\section{RESULTS}

Figure 1 shows the study population flowchart. Of the 64 subjects included in the study, $14(21.8 \%)$ had OSA, 25 (39.1\%) had isolated nocturnal hypoxemia, and $25(39.1 \%)$ did not have either of the two sleepdisordered breathing conditions.

Table 1 presents the characteristics of the study sample. All patients had mild daytime hypoxemia, according to the selection criteria of the study. The sleep-disordered breathing (OSA or isolated nocturnal hypoxemia) group did not differ from the non-sleep-disordered breathing group on any baseline characteristics, except for $\mathrm{PaO}_{2}$ as measured by arterial blood gas analysis, $\mathrm{PaO}_{2}$ being significantly lower both in the OSA group $(p=0.04)$ and in the isolated nocturnal hypoxemia group $(p=0.04)$ than in the non-sleep-disordered breathing group. However, there was no statistically significant difference in $\mathrm{PaO}_{2}$ between the OSA and isolated nocturnal hypoxemia groups $(p=1.00)$.

The median of the mean oxygen saturation as measured by oximetry during wakefulness on polysomnography was significantly lower in the OSA group ( $p=0.001)$ and the isolated nocturnal hypoxemia group $(p<0.0001)$ than in the non-sleep-disordered breathing group. However, between the OSA and isolated nocturnal hypoxemia groups, these medians were not statistically significantly different. The same results were found for mean oxygen saturation during total sleep time, during rapid eye movement (REM) sleep, and during non-REM sleep, as well as for minimum oxygen saturation, time in minutes of oxygen saturation $<90 \%$, and oxygen desaturation index during total sleep time, during REM sleep, and during non-REM sleep (Figure 2).

Sleep efficiency was reduced in all groups-OSA group: median $=70.3$ and IQR: $58.5-76.5$; isolated nocturnal hypoxemia group: median $=69.7$ and IQR: 59.8-80.6; and non-sleep-disordered breathing group: median $=70.6$ and IQR: $57.1-82.9(p=0.89)$. There were no statistically significant differences in Epworth Sleepiness Scale scores among the OSA, isolated nocturnal hypoxemia, and non-sleep-disordered breathing groups $(9.2 \pm 4.1 ; 7.2 \pm 4.3$; and $7.3 \pm$ 4.4 , respectively; $p=0.35)$. The number of snoringassociated arousals was statistically higher in the OSA

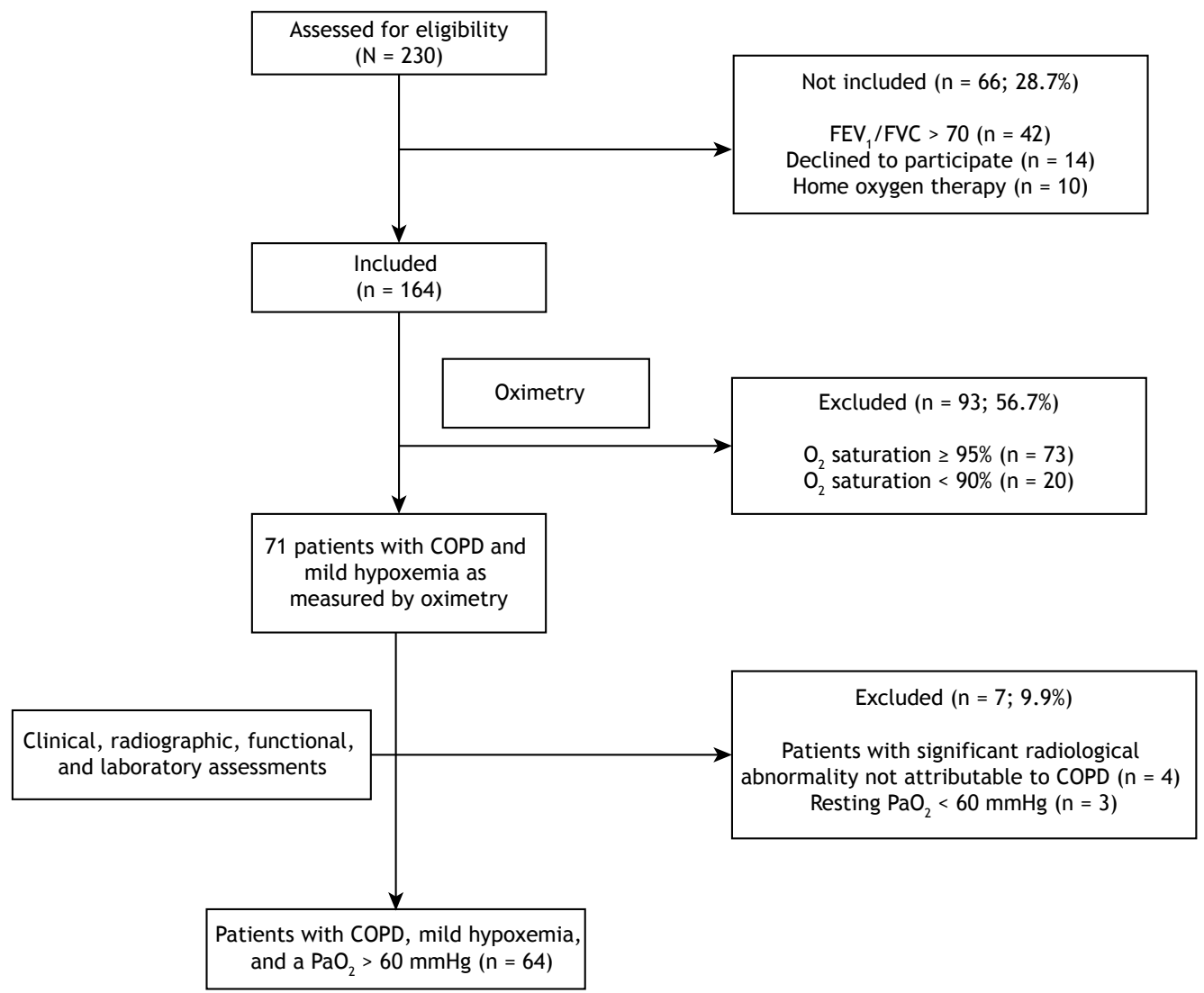

Figure 1. Study population flowchart. 
Table 1. Characteristics of the study sample. ${ }^{\mathrm{a}}$

\begin{tabular}{|c|c|c|c|c|c|}
\hline Characteristic & $\begin{array}{l}\text { Total sample } \\
\text { (n }=64)\end{array}$ & $\begin{array}{c}\text { OSA } \\
(n=14)\end{array}$ & $\begin{array}{l}\text { Subgroup } \\
\text { Nocturnal } \\
\text { hypoxemia } \\
\text { (n = 25) }\end{array}$ & $\begin{array}{l}\text { Non-SDB } \\
(n=25)\end{array}$ & $\mathbf{p}$ \\
\hline Age, years & $69.7 \pm 8.8$ & $69.9 \pm 6.1$ & $68.9 \pm 9.5$ & $70.4 \pm 9.5$ & 0.84 \\
\hline Male gender, n (\%) & $36(56.3)$ & $8(57.1)$ & $11(44)$ & $17(68)$ & 0.23 \\
\hline $\mathrm{BMI}, \mathrm{kg} / \mathrm{m}^{2}$ & $25.1 \pm 5.2$ & $26.9 \pm 6.2$ & $25.4 \pm 5.9$ & $23.8 \pm 3.5$ & 0.21 \\
\hline Neck circumference, $\mathrm{cm}$ & $36.6 \pm 4.9$ & $37.8 \pm 6.3$ & $36.5 \pm 4.0$ & $35.9 \pm 4.7$ & 0.55 \\
\hline Socioeconomic score & $17(14-24)$ & $19(16-24)$ & $16(14-19)$ & $17(13-25)$ & 0.49 \\
\hline Smoking history, pack-years & $47.5(26-60)$ & $53.3(35-60)$ & $37(22.5-60)$ & $51(30-66)$ & 0.46 \\
\hline Smokers & $17(26.6)$ & $5(35.7)$ & $9(36)$ & $3(12)$ & \\
\hline Former smokers/never smokers & $47(73.4)$ & $9(64.3)$ & $16(64)$ & $22(88)$ & 0.11 \\
\hline MAP, mmHg & $92.9 \pm 10.5$ & $95.2 \pm 12.9$ & $91.1 \pm 9.2$ & $93.3 \pm 10.4$ & 0.48 \\
\hline Hypertension, n (\%) & $37(57.8)$ & $6(42.9)$ & $17(68)$ & $14(56)$ & 0.30 \\
\hline \multicolumn{6}{|l|}{ COPD classification, $\mathrm{n}(\%)$} \\
\hline GOLD A & $6(9.4)$ & $2(14.3)$ & $2(8)$ & $2(8)$ & 0.82 \\
\hline GOLD B & $10(15.6)$ & $2(14.3)$ & $5(20)$ & $3(12)$ & \\
\hline GOLD C & $2(3.1)$ & $0(0)$ & $0(0)$ & $2(8)$ & \\
\hline GOLD D & $46(71.9)$ & $10(71.4)$ & $18(72)$ & $18(72)$ & \\
\hline Post-BD FEV ${ }_{1}, \mathrm{~L}$ & $1.29 \pm 0.6$ & $1.45 \pm 0.5$ & $1.20 \pm 0.6$ & $1.30 \pm 0.6$ & 0.45 \\
\hline Post-BD FEV ${ }_{1}, \%$ & $50.2 \pm 18.6$ & $56.5 \pm 18.4$ & $48.2 \pm 19.4$ & $48.6 \pm 17.8$ & 0.36 \\
\hline Post-BD FEV ${ }_{1} / \mathrm{FVC}, \%$ & $51.3 \pm 12.1$ & $57.1 \pm 8.8$ & $49.9 \pm 14.4$ & $49.5 \pm 10.6$ & 0.13 \\
\hline $\mathrm{PaO}_{2}, \mathrm{mmHg}$ & $71.9 \pm 9.8$ & $69.0 \pm 7.8$ & $69.6 \pm 9.9$ & $76.0 \pm 9.8$ & $0.03^{*}$ \\
\hline $\mathrm{PaCO}_{2}, \mathrm{mmHg}$ & $35.1 \pm 5.2$ & $35.8 \pm 5.9$ & $36.3 \pm 5.1$ & $33.5 \pm 4.7$ & 0.15 \\
\hline $\mathrm{O}_{2}$ saturation by $\mathrm{ABG}$ analysis, $\%$ & $93.8 \pm 2.1$ & $93.2 \pm 2.1$ & $93.5 \pm 1.9$ & $94.5 \pm 2.1$ & 0.11 \\
\hline Pulmonary hypertension, n (\%) & $3(4.7)$ & $1(7.1)$ & $2(8)$ & $0(0)$ & \\
\hline Normal PASP, n (\%) & $30(46.9)$ & $7(50)$ & $14(56)$ & $9(36)$ & 0.20 \\
\hline Indeterminate PASP, n (\%) ${ }^{c}$ & $31(48.4)$ & $6(42.9)$ & $9(36)$ & $16(64)$ & \\
\hline Desaturation during the $6 \mathrm{MWT}$ & $17(26.6)$ & $4(28.6)$ & $8(32)$ & $5(20)$ & 0.67 \\
\hline $6 \mathrm{MWD}, \%$ of predicted & $92.2(82.4-107.7)$ & $92.4(84.8-102.8)$ & $90.8(82.4-107.6)$ & $92.2(82.1-108.3)$ & 0.98 \\
\hline CAT & $17 \pm 7.1$ & $14.4 \pm 6.6$ & $18 \pm 6.8$ & $17.4 \pm 7.7$ & 0.31 \\
\hline
\end{tabular}

OSA: obstructive sleep apnea; SDB: sleep-disordered breathing; BMI: body mass index; MAP: mean arterial pressure; GOLD: Global Initiative for Chronic Obstructive Lung Disease; BD: bronchodilator; ABG: arterial blood gas; PASP: pulmonary artery systolic pressure; 6MWT: six-minute walk test; 6MWD: six-minute walk distance; and CAT: COPD Assessment Test. ${ }^{a}$ Values expressed as mean \pm SD or as median (interquartile range), except where otherwise indicated. ${ }^{b}$ Pulmonary hypertension was defined as a PASP $>40 \mathrm{mmHg}$. 'Indeterminate PASP was defined as the patient having no tricuspid regurgitation.

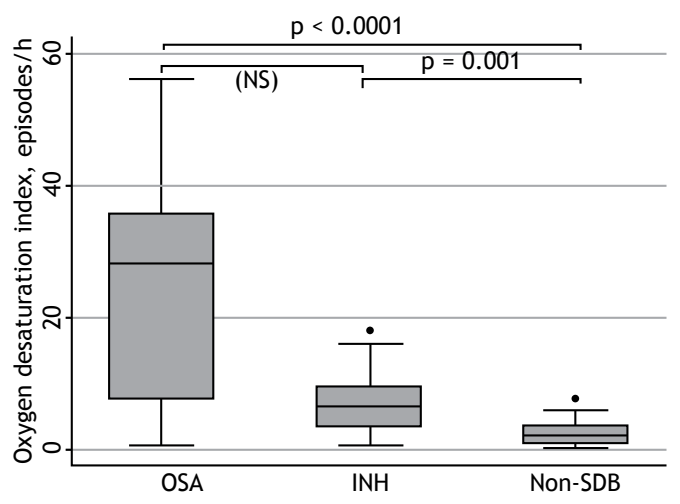

Figure 2.Oxygen desaturation index during rapid eye movement (REM) sleep and non-REM sleep in the obstructive sleep apnea (OSA), isolated nocturnal hypoxemia (INH), and non-sleep-disordered breathing (SDB) groups. NS: not significant.

group than in the isolated nocturnal hypoxemia group $(p=0.001)$ and the non-sleep-disordered breathing group ( $p=0.0001)$, but there was no statistically significant difference in this number between the isolated nocturnal hypoxemia and non-sleep-disordered breathing groups $(p=0.20)$.

Correlation analysis showed that $\mathrm{PaO}_{2}$ correlated moderately with mean oxygen saturation during total sleep time $(r=0.45 ; p=0.0002)$, mean oxygen saturation during REM sleep $(r=0.43 ; p=0.001)$, and mean oxygen saturation during non-REM sleep $(r$ $=0.42 ; p=0.001$ ). In addition, a moderate correlation was observed between the AHI and the number of snore arousals $(r=0.53 ; p=0.001)$. Multiple linear regression analysis was performed between the $\mathrm{AHI}$ as a continuous, dependent variable for OSA and clinical predictors (number of snoring-associated arousals, Epworth Sleepiness Scale score, age, body mass index, six-minute walk distance, neck circumference, oxygen saturation, $\mathrm{PaO}_{2}, \mathrm{PaCO}_{2}$, COPD Assessment Test score, $\mathrm{FEV}_{1}, \mathrm{FEV}_{1} / \mathrm{FVC}$ ratio, and mean arterial pressure), and no statistically significant coefficient 
was found. The same results were found using other variables as dependent variables (time in minutes of oxygen saturation $<90 \%$ and time in minutes of oxygen saturation $<85 \%$, respectively, during total sleep time, during REM sleep, and during non-REM sleep) and the same clinical predictors.

When considering the baseline characteristics, the groups differed only in $\mathrm{PaO}_{2}$; therefore, a logistic regression analysis was conducted to determine whether $\mathrm{PaO}_{2}$ could independently predict sleep-disordered breathing ( $\mathrm{OR}=0.93 ; 95 \% \mathrm{CI}: 0.87-0.99 ; \mathrm{p}=0.02$ ). After determination of the best cut-off point to identify sleep-disordered breathing $\left(\mathrm{PaO}_{2} \leq 70 \mathrm{mmHg}\right)$, the model $(\mathrm{OR}=4.59 ; 95 \% \mathrm{CI}: 1.54-13.67 ; \mathrm{p}=0.01)$ had a specificity of $73.9 \%$ (95\% CI: $51.6-89.8)$; a sensitivity of $63.4 \%$ (95\% CI: $46.9-77.9)$; a positive predictive value of $81.3 \%$ (95\% CI: $67.7-90.0)$; and a negative predictive value of $53.1 \%$ (95\% CI: 41.4-64.4). The area under the ROC curve was 0.69 (95\% CI: $0.57-0.80$ ), and the proportion of correctly classified observations was $67.2 \%$.

\section{DISCUSSION}

In our study sample, $60 \%$ of the patients with COPD for whom polysomnography was not formally indicated had sleep-disordered breathing. The prevalence of nocturnal hypoxemia found in the present sample (39\%) can be considered high. ${ }^{(6-14)}$ This is because the wide variation reported in the literature (from $27 \%$ to $84 \%$ ) can be explained by the use of different definitions and inclusion criteria. For instance, Chaouat et al.(9) used severe daytime hypoxemia $\left(\mathrm{PaO}_{2}<60 \mathrm{mmHg}\right)$ as an inclusion criterion and found a prevalence of $70 \%$, whereas Vos et al. ${ }^{\left({ }^{8}\right)}$ included patients with OSA and patients with central hypoventilation in the group of those with nocturnal desaturation and did not use $\mathrm{PaO}_{2}$ as an inclusion or exclusion criterion, finding a prevalence of $84 \%$. Other studies have used pulse oximetry rather than polysomnography to diagnose nocturnal hypoxemia in small samples and found prevalence rates ranging from $47 \%$ to $52 \%$. $^{(10,11,13)}$ In contrast, authors using methodologies similar to that of the present study have found similar prevalence rates. ${ }^{(7,12)}$

In the present study, $\mathrm{PaO}_{2}$ was the independent variable predictive of sleep-disordered breathing among the patients with COPD and mild daytime hypoxemia. The high positive predictive value found $(81.3 \%)$ demonstrates that the cut-off point of $\leq 70 \mathrm{mmHg}$ can be useful in epidemiological settings where the prevalence of sleep-disordered breathing is high, which has been demonstrated to be the usual finding. ${ }^{(8-14)}$ A previous study showed that subjects with a resting oxygen saturation $\geq 95 \%$ seldom have isolated nocturnal hypoxemia, which suggests that the investigation of this condition is unnecessary in this subgroup of patients. ${ }^{(11)}$ According to the current indications for the use of home oxygen therapy in COPD, patients with an oxygen saturation $<90 \%\left(\mathrm{PaO}_{2}<60 \mathrm{mmHg}\right)$ should be evaluated and often require home oxygen therapy. (29) In our study sample, the subgroup of patients with COPD and daytime oxygen saturation between $90 \%$ and $94 \%$ (mild daytime hypoxemia) had a high prevalence of sleep-disordered breathing and benefited from polysomnography, although polysomnography in this context is not formally recommended by the literature. Several authors have attempted to predict nocturnal hypoxemia on the basis of patient characteristics or daytime physiological measurements. $(6,7,10-14)$ However, this remains a controversial point, because although some authors have concluded that nocturnal desaturation cannot be predicted by any daytime functional measurement or anthropometric measurement, others have demonstrated that resting oxygen saturation and/or resting $\mathrm{PaO}_{2}$ can predict nocturnal desaturation, although not accurately (correlation coefficients of $0.51-0.78){ }^{(6,7,10-13)}$ This moderate correlation and the limited prediction ability found in the present study have been confirmed by other authors, suggesting that other factors can influence oxygenation during sleep. ${ }^{(6,7,11,13)}$ Chaouat et al. ${ }^{(9)}$ found that a high body mass index (BMI) was associated with nocturnal desaturation, and several authors have demonstrated that a high $\mathrm{PaCO}_{2}$ can predict nocturnal desaturation. . $^{(71,14)}$ The present study found no association between $\mathrm{PaCO}_{2}$ and nocturnal hypoxemia. This could be due to a selection bias, given that the patients in our sample had less severe COPD than did those included in other studies evaluating patients with a $\mathrm{PaO}_{2}<60 \mathrm{mmHg} \cdot{ }^{(7,9,11,14)}$ The same may be true for BMI. It has been demonstrated that overweight and obesity can reduce FVC and expiratory reserve volume because of the loss in baseline lung volume. (28) However, the subjects in the present sample had a mean BMI of $25.1 \mathrm{~kg} / \mathrm{m}^{2}$, which is considered normal. Scott et al. ${ }^{(30)}$ showed that desaturation during the 6MWT was associated with nocturnal hypoxemia (OR $=3.77,95 \% \mathrm{CI}: 1.87-7.62)$. Although it is possible to suggest that a lower baseline oxygen saturation may leave subjects prone to having desaturation at night and during exercise, the physiological factors related to the two conditions are different. During exercise, increased peripheral oxygen extraction, worsening of the ventilation/perfusion ratio, and dynamic hyperinflation are the causes of hypoxemia, ${ }^{(31)}$ whereas, during sleep, reduced ventilation due to decreased responsiveness of the respiratory center, reduced accessory muscle contribution, decreased functional residual capacity, and increased closing volume, especially during REM sleep, are the factors producing hypoxemia. ${ }^{(32)}$ The present study and two other studies also failed to demonstrate that desaturation during exercise can predict nocturnal hypoxemia. ${ }^{(10,13)}$

Although the prevalence of OSA found in the present study $(21.8 \%)$ is within the range reported in the literature, it is higher than that reported in some studies, which is probably due to the prevalence of males and advanced age subjects in our sample, as the prevalence of OSA is higher in males and increases with age. ${ }^{(32)}$ 
The relatively high prevalence of OSA found in the patients with COPD and mild hypoxemia (22\%) and the reduced prevalence of clinical characteristics classically associated with OSA-systemic arterial hypertension (SAH), a high BMI, a large neck circumference, and daytime sleepiness-in this subgroup are noteworthy. The OSA group did not show a higher prevalence of $\mathrm{SAH}$ or have a higher level of systemic arterial pressure compared with the other groups. In addition, the results for BMI, neck circumference, and the Epworth Sleepiness Scale in the OSA group were not statistically different from those in the other groups. Venkateswaran \& Tee, ${ }^{(33)}$ in comparing COPD patients with and without OSA, also found similar results. Because of systemic inflammation, patients with COPD may have a reduction in BMI and a predisposition to $\mathrm{SAH}_{1}^{(34)}$ and, because of the respiratory disease, they may have decreased sleep efficiency. ${ }^{(11)}$ Therefore, the high prevalence of $\mathrm{SAH}$, the lower BMI, with a consequently smaller neck circumference, and the lower sleep efficiency observed in all groups can explain the absence of a typical clinical profile of OSA in patients with COPD.

Measurement of oxygen saturation is routinely used for the evaluation of patients with COPD because of its many advantages over blood gas analysis (it is noninvasive, painless, and inexpensive, provides immediate results, and is widely available). ${ }^{(35)}$ In view of the findings of the present study, and in the light of the established value of oximetry as an indication for oxygen supplementation and for hospitalization in cases of acute exacerbation, ${ }^{(36)}$ oximetry could also be used to screen patients with stable COPD for sleep-disordered breathing. When oximetry readings are between $90 \%$ and $94 \%$, blood gas analysis could be requested. $\mathrm{A} \mathrm{PaO}_{2}$ finding of $\leq 70 \mathrm{mmHg}$ is associated with the presence of sleep-disordered breathing and would be an indication for requesting polysomnography.

Despite being considered the gold standard for the diagnosis of OSA syndrome, polysomnography is an expensive and technically complex test; therefore, laboratories specializing in polysomnography are scarce. To overcome this obstacle, clinical screening questionnaires should be used to identify patients at high risk for OSA, who would benefit from receiving a diagnosis and treatment as soon as possible. Studies demonstrate that portable devices have proven to be able to provide a diagnosis equivalent to that provided by in-laboratory polysomnography, at least in patients with a high likelihood of OSA. ${ }^{(37,38)}$

The present study has several limitations. All polysomnography tests were single-night measurements. Sleep changes associated with the initial experience of patients in a sleep laboratory are well known; therefore, in some studies, the first night is only used for acclimatizing patients. If sleep is disturbed in COPD patients, arousals may prevent deep sleep and desaturation. As a result, we could have underestimated nocturnal oxygenation by evaluating a single night's sleep. However, most studies that used polysomnography to diagnose nocturnal hypoxemia in patients with COPD made a single-night assessment, $(6,7,9,10,13,14)$ and some authors have shown that there are no significant differences in mean oxygen saturation between consecutive and non-consecutive nights in the sleep laboratory. ${ }^{(35)}$ Thus, the use of single-night polysomnography may not have affected our results. Our study was designed to assess the prevalence of sleep-disordered breathing in a subgroup of COPD patients with minor functional impairment (mild hypoxemia). The exclusion of COPD patients with moderate or severe hypoxemia may have introduced a selection bias, because patients, according to daily clinical practice, have various levels of hypoxemia, ranging from normoxemia to severe hypoxemia. In addition, for proper analysis of prevalence, there would be the need for an external control group.

In conclusion, the prevalence of sleep-disordered breathing in our sample of patients with COPD and mild hypoxemia was found to be high $(61 \%)$, and a $\mathrm{PaO}_{2}$ finding of $\leq 70 \mathrm{mmHg}$ on arterial blood gas analysis was significantly associated with sleep-disordered breathing $(\mathrm{OR}=4.59 ; 95 \% \mathrm{CI}: 1.54-13.67 ; \mathrm{p}=0.01)$. These results indicate that this subgroup of patients with COPD and mild hypoxemia would benefit from sleep studies.

\section{REFERENCES}

1. Corsonello A, Antonelli Incalzi R, Pistelli R, Pedone C, Bustacchini S, Lattanzio F. Comorbidities of chronic obstructive pulmonary disease. Curr Opin Pulm Med. 2011;17 Suppl 1:S21-8. https://doi. org/10.1097/01.mcp.0000410744.75216.d0

2. Global Initiative for Chronic Obstructive Lung Disease - GOLD [homepage on the Internet]. Bethesda: GOLD [cited 2016 Jan 21]. Global Strategy for the Diagnosis, Management, and Prevention of COPD 2014. Available from: http://www.goldcopd.org/.

3. Agusti A, Hedner J, Marin JM, Barbé F, Cazzola M, Rennard S. Nighttime symptoms: a forgotten dimension of COPD. Eur Respir Rev. 2011;20(121):183-94. https://doi.org/10.1183/09059180.00004311

4. Owens RL, Malhotra A. Sleep-disordered breathing and COPD: the overlap syndrome. Respir Care. 2010;55(10):1333-44; discussion 1344-6.

5. Marrone O, Salvaggio A, Insalaco G. Respiratory disorders during sleep in chronic obstructive pulmonary disease. Int J Chron Obstruct Pulmon Dis. 2006;1(4):363-72. https://doi.org/10.2147/ copd.2006.1.4.363

6. Levi-Valensi P, Weitzenblum E, Rida Z, Aubry P, Braghiroli A, Donner $C$, et al. Sleep-related oxygen desaturation and daytime pulmonary haemodynamics in COPD patients. Eur Respir J. 1992;5(3):301-7. Erratum in: Eur Respir J. 1992;5(5):645.

7. Fletcher EC, Miller J, Divine GW, Fletcher JG, Miller T. Nocturna oxyhemoglobin desaturation in COPD patients with arterial oxygen tensions above $60 \mathrm{~mm} \mathrm{Hg}$. Chest. 1987;92(4):604-8. https://doi. org/10.1378/chest.92.4.604

8. Vos PJ, Folgering HT, van Herwaarden CL. Sufficient indication of nocturnal oxygen saturation and breathing pattern in COPD patients, from a single night's study. Respir Med. 1995;89(9):615-6. https:// doi.org/10.1016/0954-6111(95)90229-5

9. Chaouat A, Weitzenblum E, Kessler R, Charpentier C, Ehrhart M Levi-Valensi $P$, et al. Sleep-related $\mathrm{O} 2$ desaturation and daytime pulmonary haemodynamics in COPD patients with mild hypoxaemia. Eur Respir J. 1997;10(8):1730-5. https://doi.org/10.1183/09031936.9 7.10081730

10. Mueller Pde T, Gomes MD, Viegas CA, Neder JA. Systemic effects of 
nocturnal hypoxemia in patients with chronic obstructive pulmonary disease without obstructive sleep apnea syndrome. J Bras Pneumol. 2008;34(8):567-74

11. Lewis CA, Fergusson W, Eaton T, Zeng I, Kolbe J. Isolated nocturnal desaturation in COPD: prevalence and impact on quality of life and sleep. Thorax. 2009;64(2):133-8. https://doi.org/10.1136/ thx.2007.088930

12. Lacasse $Y$, Sériès F, Vujovic-Zotovic N, Goldstein R, Bourbeau J, Lecours $\mathrm{R}$, et al. Evaluating nocturnal oxygen desaturation in COPD -revised. Respir Med. 2011;105(9):1331-7. https://doi.org/10.1016/j. rmed.2011.04.003

13. Zanchet RC, Viegas CA. Nocturnal desaturation: predictors and the effect on sleep patterns in patients with chronic obstructive pulmonary disease and concomitant mild daytime hypoxemia. $J$ Bras Pneumol. 2006;32(3):207-12. https://doi.org/10.1590/S180637132006000300006

14. Toraldo DM, Nicolardi G, De Nuccio F, Lorenzo R, Ambrosino N Pattern of variables describing desaturator COPD patients, as revealed by cluster analysis. Chest. 2005;128(6):3828-37. https://doi. org/10.1378/chest.128.6.3828

15. Sanders $M H$, Newman $A B$, Haggerty $C L$, Redline $S$, Lebowitz $M$, Samet J, et al. Sleep and sleep-disordered breathing in adults with predominantly mild obstructive airway disease. Am J Respir Crit Care Med. 2003;167(1):7-14. https://doi.org/10.1164/rccm.2203046

16. Bednarek M, Plywaczewski $R$, Jonczak $L$, Zielinski J. There is no relationship between chronic obstructive pulmonary disease and obstructive sleep apnea syndrome: a population study. Respiration. 2005;72(2):142-9. https://doi.org/10.1159/000084044

17. Machado MC, Vollmer WM, Togeiro SM, Bilderback AL, Oliveira MV Leitão FS, et al. CPAP and survival in moderate-to-severe obstructive sleep apnoea syndrome and hypoxaemic COPD. Eur Respir J. 2010;35(1):132-7. https://doi.org/10.1183/09031936.00192008

18. López-Acevedo MN, Torres-Palacios A, Elena Ocasio-Tascón M, Campos-Santiago Z, Rodríguez-Cintrón W. Overlap syndrome: an indication for sleep studies? : A pilot study. Sleep Breath 2009;13(4):409-13. https://doi.org/10.1007/s11325-009-0263-5

19. Gay PC. Chronic obstructive pulmonary disease and sleep. Respir Care. 2004;49(1):39-51; discussion 51-2.

20. Bestall JC, Paul EA, Garrod R, Garnham R, Jones PW, Wedzicha JA. Usefulness of the Medical Research Council (MRC) dyspnoea scale as a measure of disability in patients with chronic obstructive pulmonary disease. Thorax. 1999;54(7):581-6. https://doi. org/10.1136/thx.54.7.581

21. Jones PW, Harding G, Berry P, Wiklund I, Chen WH, Kline Leidy N. Development and first validation of the COPD Assessment Test. Eur Respir J. 2009;34(3):648-54. https://doi. org/10.1183/09031936.00102509

22. Associação Brasileira de Empresas de Pesquisa. Critério de classificação econômica Brasil. São Paulo: Associação Nacional de Empresas de Pesquisa; 2009.

23. Johns MW. A new method for measuring daytime sleepiness: The Epworth sleepiness scale. Sleep. 1991;14(6):540-5.
24. Burge S, Wedzicha JA. COPD exacerbations: definitions and classifications. Eur Respir J Suppl. 2003:41:46s-53s. https://doi.org /10.1183/09031936.03.00078002

25. Centers for Disease Control and Prevention (CDC). Cigarette smoking among adults--United States, 1992, and changes in the definition of current cigarette smoking. MMWR Morb Mortal Wkly Rep. 1994;43(19):342-6. Erratum in: MMWR Morb Mortal Wkly Rep. 1994;43(43):801-3

26. Poulain M, Durand F, Palomba B, Ceugniet F, Desplan J, Varray A, et al. 6-minute walk testing is more sensitive than maximal incremental cycle testing for detecting oxygen desaturation in patients with COPD. Chest. 2003;123(5):1401-7. https://doi.org/10.1378/ chest.123.5.1401

27. American Academy of Sleep Medicine. International classification of sleep disorders. 3rd ed. Darien, IL: American Academy of Sleep Medicine; 2014.

28. Lwanga SK, Lemeshow S. Sample size determination in health studies: a practical manual. Geneva: World Health Organization; 1991.

29. Zammit $\mathrm{C}$, Liddicoat $\mathrm{H}$, Moonsie I, Makker $\mathrm{H}$. Obesity and respiratory diseases. Int J Gen Med. 2010;3:335-43.

30. Scott AS, Baltzman MA, Chan R, Wolkove N. Oxygen desaturation during a 6 min walk test is a sign of nocturnal hypoxemia. Can Respir J. 2011;18(6):333-7. https://doi.org/10.1155/2011/242636

31. Kent BD, Mitchell PD, McNicholas WT. Hypoxemia in patients with COPD: cause, effects, and disease progression. Int J Chron Obstruct Pulmon Dis. 2011;6:199-208.

32. Bhullar S, Phillips B. Sleep in COPD patients. COPD. 2005;2(3):355 61. https://doi.org/10.1080/15412550500274836

33. Venkateswaran S, Tee A. Overlap syndrome between chronic obstructive pulmonary disease and obstructive sleep apnoea in a Southeast Asian teaching hospital. Singapore Med J. 2014;55(9):488 92. https://doi.org/10.11622/smedj.2014117

34. Barnes PJ, Celli BR. Systemic manifestations and comorbidities of COPD. Eur Respir J. 2009;33(5):1165-85. https://doi. org/10.1183/09031936.00128008

35. Gothe B, Hanekamp LM, Cherniack NS. Reproducibility of ventilatory measurements during sleep on different nights in patients with chronic obstructive pulmonary disease. J Lab Clin Med. 1987:109(5):608-16.

36. Plüddemann A, Thompson M, Heneghan C, Price C. Pulse oximetry in primary care: primary care diagnostic technology update. $\mathrm{Br} \mathrm{J}$ Gen Pract. 2011;61(586):358-9. https://doi.org/10.3399/bjgp11X572553

37. Polese JF, Santos-Silva R, Kobayashi RF, Pinto IN, Tufik S Bittencourt LR. Portable monitoring devices in the diagnosis of obstructive sleep apnea: current status, advantages, and limitations. J Bras Pneumol. 2010;36(4):498-505. https://doi.org/10.1590/S180637132010000400017

38. Corral-Peñafiel J, Pepin JL, Barbe F. Ambulatory monitoring in the diagnosis and management of obstructive sleep apnoea syndrome. Eur Respir Rev. 2013:22(129):312-24. https://doi. org/10.1183/09059180.00004213 